\title{
Fluorine NMR Spectroscopy Enables to Quantify the Affinity Between DNA and Proteins in Cell Lysate
}

\author{
Hannah Welte, ${ }^{[a]}$ Pia Sinn ${ }^{[a]}$ and Michael Kovermann ${ }^{*[a]}$
}

\begin{abstract}
The determination of the binding affinity quantifying the interaction between proteins and nucleic acids is of crucial interest in biological and chemical research. Here, we have made use of site-specific fluorine labeling of the cold shock protein from Bacillus subtilis, BsCspB, enabling to directly monitor the interaction with single stranded DNA molecules in cell lysate. High-resolution ${ }^{19} \mathrm{~F}$ NMR spectroscopy has been applied to exclusively report on resonance signals arising from the protein under study. We have found that this experimental approach advances the reliable determination of the binding
\end{abstract}

\section{Introduction}

Nucleic acid-to-protein interactions play an eminent role in living organisms. ${ }^{[1]}$ The concerted interplay between proteins and nucleic acids controls e.g. the expression of the genome in cellular metabolism, replication and development processes in a highly regulated and organized manner. ${ }^{[1]}$ Generally, proteins interacting with nucleic acids can be divided into two distinct classes: (i) those that interact specifically with nucleotide sequences and (ii) those that interact non-sequencespecifically. ${ }^{[1-2]}$ However, nucleic acid-to-protein interactions take place in vivo in the presence of various kinds of (macro) molecules possessing concentrations of up to $400 \mathrm{~g} / \mathrm{L}$ in bacteria $^{[3]}$ and $50-200 \mathrm{~g} / \mathrm{L}$ in eukaryotic cells ${ }^{[4]}$ potentially influencing the molecular interaction under observation. ${ }^{[5]}$ Contrary, the ligand affinity which characterizes DNA or RNA binding proteins is usually determined under dilute conditions in vitro ${ }^{[6]}$ and, therefore, potential effects due to e.g. changes in the viscosity or the existence of non-specific interactions involving adjacent (macro)molecules are completely neglected. However, the impact of a highly crowded environment on thermodynamic stability, structural properties and the capacity of intermolecular interactions of proteins has been shown by many studies even at an all atom basis. ${ }^{[5,7]}$ For this reason, it can be anticipated that interaction studies conducted under

[a] H. Welte, P. Sinn, Prof. Dr. M. Kovermann

Department of Chemistry

University of Konstanz

Universitätsstrasse 10, 78467 Konstanz (Germany)

E-mail: michael.kovermann@uni-konstanz.de

Supporting information for this article is available on the WWW under https://doi.org/10.1002/cbic.202100304

of (c) 2021 The Authors. ChemBioChem published by Wiley-VCH GmbH. This is an open access article under the terms of the Creative Commons Attribution Non-Commercial NoDerivs License, which permits use and distribution in any medium, provided the original work is properly cited, the use is noncommercial and no modifications or adaptations are made. affinity between single stranded DNA molecules and its target protein in this complex biological environment by intertwining analyses based on NMR chemical shifts, signal heights, line shapes and simulations. We propose that the developed experimental platform offers a potent approach for the identification of binding affinities characterizing intermolecular interactions in native surroundings covering the nano-to-micromolar range that can be even expanded to in cell applications in future studies.

dilute conditions may not precisely report on binding processes taking place in vivo. Consequently, there exists a strong interest to perform such interaction studies directly in a cellular environment. However, the quantitative determination of the affinity of DNA or RNA binding proteins directly in the cell or in a cell-like environment holds several experimental challenges e.g. due to high background signals of the surrounding molecules and the viability of the molecules under study. ${ }^{[8]}$

Fluorine $\left({ }^{19} \mathrm{~F}\right)$ nuclear magnetic resonance (NMR) spectroscopy offers an excellent tool to study proteins in such complex environments since fluorine is not naturally found in cells. ${ }^{[9]}$ Moreover, ${ }^{19} \mathrm{~F}$ nuclei are $100 \%$ naturally abundant and own a sensitivity of about $83 \%$ compared to protons making this nucleus to an ideal choice for the experiments intended here. ${ }^{[10]}$

Our study focuses on the cold shock protein B from Bacillus subtilis ( $B s C s p B)$ which three-dimensional structure has been determined by both X-ray crystallography and NMR spectroscopy. ${ }^{[1]}$ Cold shock proteins are known to bind to nucleic acids and function as transcription factors and transcription antiterminators as well as RNA chaperons. ${ }^{[12]}$ Thus, it was found that $B s C s p B$ binds preferentially to poly-thymidine stretches of six to seven nucleotides in length in an $1: 1$ stoichiometric ratio ${ }^{[13]}$ and the three-dimensional structure of $B s C s p B$ could be solved e.g. in presence of six consecutive thymidines $\Pi T T$ TाT (labeled as dT6) by X-ray crystallography (Figure 1). ${ }^{[14]}$ The determined binding surface consists of a hydrophobic platform built by aromatic and basic residues (K7, W8, K13, F15, F17, F27, H29, F30 and R56) that are mainly located in the nucleic acid binding motifs RNP-1 (K13-V20) and RNP-2 (V26-F30). ${ }^{[15]}$ The side chains of these residues are surface exposed and interact with nucleobases by stacking interactions and hydrogen bonds. ${ }^{[13 d, 14 b]}$ The discrimination between ssDNA and ssRNA binding to $B s C s p B$ is based on the substitution of thymidine with uracil. ${ }^{[14 b]}$

Consequently, we have here combined the inherent advantages of ${ }^{19} \mathrm{~F}-\mathrm{NMR}$ spectroscopy with the observation of a key 


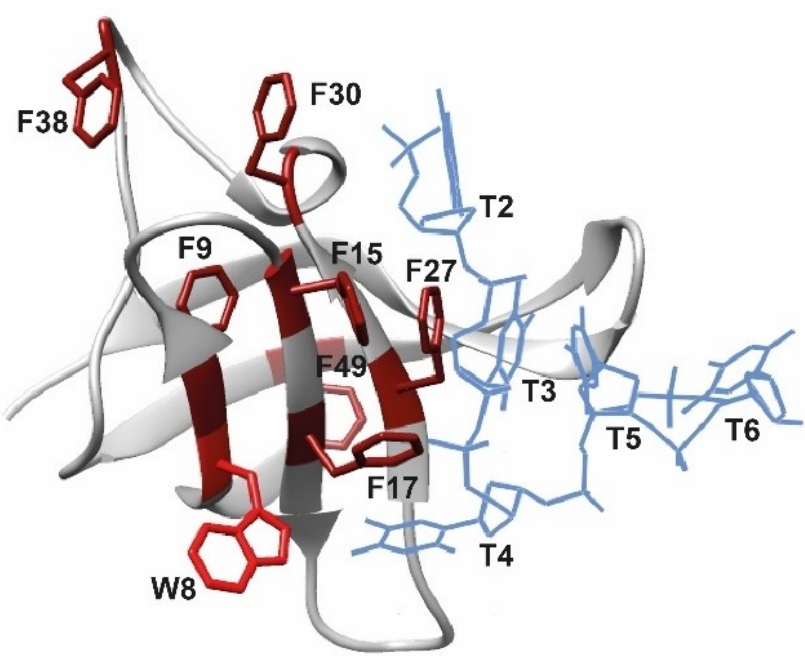

Figure 1. Complex formed between $B s C s p B$ (cartoon mode, colored in gray) and dT6 (stick mode, colored in light blue). ${ }^{[13 a]}$ Five thymidines composing dT6 are highlighted by T2-T6. This study focuses on fluorine labeled BsCspB either using single tryptophan $\left(5-{ }^{19} \mathrm{~F}-\mathrm{Trp}-\mathrm{Bs} \mathrm{CspB}\right)$ or seven phenylalanine sites $\left(4-{ }^{19} \mathrm{~F}-\mathrm{Phe}-\mathrm{Bs} \mathrm{CspB}\right)$. Side chains are labeled using position in the primary sequence, highlighted in stick mode and colored in red. PDB code 2 es 2 and PyMOL Molecular Graphics System, Schrödinger, LCC have been used to prepare this figure.

biological interaction taking place in a cellular environment. Therefore, $B s C s p B$ has been fluorine labeled at tryptophan $\left(5-{ }^{19} \mathrm{~F}-\mathrm{Trp}-\mathrm{Bs} \mathrm{CspB}\right)$ or phenylalanine positions $\left(4-{ }^{19} \mathrm{~F}-\mathrm{Phe}-\mathrm{Bs} \mathrm{CspB}\right)$ depicting key sites for the interaction with oligonucleotides. ${ }^{[16]}$ It has been shown before that neither the structure, stability or the folding kinetics is changed when fluorine modified $B s C s p B$ is compared with wild type protein. ${ }^{[17]}$ Note that fluorine labeled $B s C s p B$ has been already successfully applied also in cell lysate to determine overall thermodynamic stability by using ${ }^{19} \mathrm{~F}$ NMR spectroscopy. ${ }^{[18]}$ Here, fluorine labeled BsCspB (Figure 1) is used to investigate, first, the potential effect of fluorine labeling on protein-to-ligand binding properties by applying fluorescence and NMR spectroscopy under dilute conditions. We then moved on to the investigation of the binding affinity of oligothymidines to $B s C s p B$ in cell lysate by using chemical shift, signal height and line shape information provided by fluorine NMR resonance signals. We found that the here presented workflow enables the reliable quantitative determination of the binding affinity characterizing nucleic acid-to-protein interaction in a complex biological environment. Moreover, the targeted recognition of single stranded DNA by its inherent binding partner persists even in highly concentrated cell lysate. The combination of fluorine labeled proteins and ${ }^{19} \mathrm{~F}$ NMR spectroscopy acts for this reason as an excellent tool to probe ligand binding affinity in native surroundings in a quantitative manner.

\section{Results and Discussion}

In a first step, we have used fluorescence spectroscopy to obtain insights into the interaction of single stranded DNA
(ssDNA) with fluorine labeled $4-{ }^{19} \mathrm{~F}-\mathrm{Phe}-\mathrm{BsCspB}$ as well as $5-{ }^{19} \mathrm{~F}-$ $\operatorname{Trp}-B s C s p B$ under dilute conditions. This experimental setup enables the precise determination of the binding affinity $\left(K_{\mathrm{D}}\right.$ value) and thereby a direct comparison to data regarding binding of ssDNA to wild type $B s \operatorname{CspB}^{[13 c]}$ is accessible. As a result, the $K_{\mathrm{D}}$ values reporting on the interaction of dT4 (four consecutive thymidines), dT5 (five consecutive thymidines), and dT6 to $4-{ }^{19} \mathrm{~F}-\mathrm{Phe}-\mathrm{BsCspB}$ (Figure S1A-E) as $5-{ }^{19} \mathrm{~F}-\operatorname{Trp}-\mathrm{BsCspB}$ (Figures 2 and $\mathrm{S} 2 \mathrm{~A}-\mathrm{C}$ ) display binding affinities which increase with increasing length of the oligonucleotide under study and mirror, in parallel, quantities found for the interaction to wild type protein (Table 1). Solely the interaction of dT7 (seven consecutive thymidines) to $4-{ }^{19} \mathrm{~F}-\mathrm{Phe}-\mathrm{Bs} \mathrm{CspB}$ (Figure $\mathrm{S} 1 \mathrm{~B}, \mathrm{~F}$ ) as $5-{ }^{19} \mathrm{~F}$-Trp-BsCspB (Figures 2 and S2D) differs by one order of magnitude compared to wild type BsCspB (Table 1) but still possesses by far the strongest affinity of all oligonucleotides

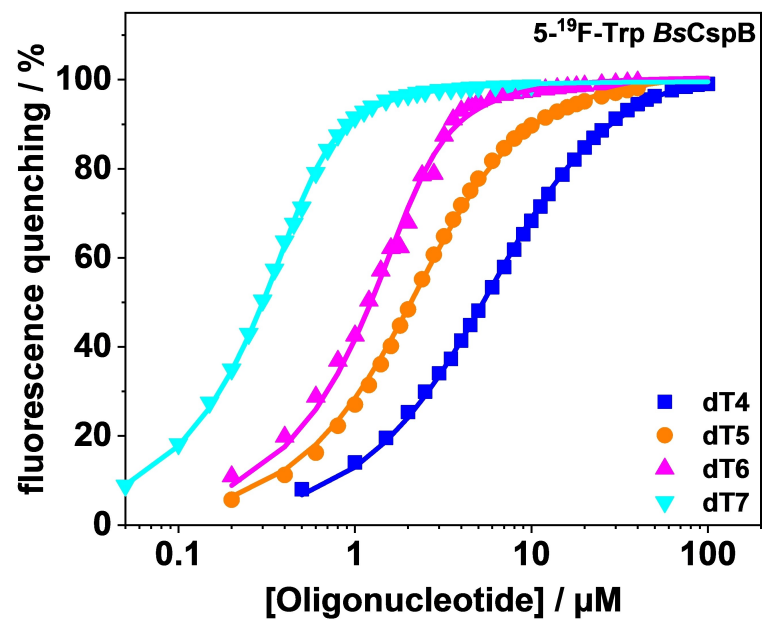

Figure 2. Probing the interaction between oligothymidines varying in length and $5-{ }^{19} \mathrm{~F}-\mathrm{Trp}-\mathrm{Bs} \mathrm{CspB}$ by applying fluorescence spectroscopy in equilibrium at $T=298 \mathrm{~K}$. The quench of intrinsic fluorescence of $5-{ }^{19} \mathrm{~F}-\mathrm{Trp}-\mathrm{Bs} \mathrm{CspB}$ has been determined for adding dT4 (colored in blue, rectangles), dT5 (colored in orange, circles), dT6 (colored in pink, triangles with tip to top) and dT7 (colored in cyan, triangles with tip to bottom) under dilute conditions. Fitting of eq. (S1) to the experimental data is represented in continuous line mode. Results of the fitting procedure are given in Table 1. Concentration of $5-{ }^{19} \mathrm{~F}-\mathrm{Trp}-\mathrm{Bs} \mathrm{CspB}$ has been set to $3 \mu \mathrm{M}$ (for the case of dT4), $2 \mu \mathrm{M}$ (for the case of $\mathrm{dT} 5$ and $\mathrm{dT} 6$ ) as to $0.5 \mu \mathrm{M}$ (for the case of dT7).

Table 1. Binding affinity, $K_{\mathrm{D}}$ in $\mathrm{nM}$ and corresponding changes in free energy, $\Delta G$, of $4-{ }^{19} \mathrm{~F}-\mathrm{Phe}-\mathrm{Bs} \mathrm{CspB}$ and $5-{ }^{19} \mathrm{~F}-\mathrm{Trp}-\mathrm{Bs} \mathrm{CspB}$ regarding the interaction with different oligonucleotides obtained using intrinsic tryptophan fluorescence titration experiments performed at $T=298 \mathrm{~K}$. The concentration of fluorine labeled $B s C s p B$ was set to 3 or $3.5 \mu \mathrm{M}$ (for the case of dT4), to $2 \mu \mathrm{M}$ (for the case of $\mathrm{dT} 5$ and dT6) as to $0.5 \mu \mathrm{M}$ (for the case of dT7).

\begin{tabular}{|lllll|} 
& dT4 & dT5 & dT6 & dT7 \\
\hline $4-{ }^{19} \mathrm{~F}-$ Phe-BsCspB & $6400 \pm 400$ & $500 \pm 50$ & $240 \pm 20$ & $30 \pm 10$ \\
$\Delta G / \mathrm{kJ} / \mathrm{mol}$ & 12.5 & 18.8 & 20.7 & 25.8 \\
$5-{ }^{-1} \mathrm{~F}-T r p-B s C s p B$ & $3900 \pm 100$ & $1120 \pm 30$ & $240 \pm 10$ & $49 \pm 2$ \\
$\Delta G / \mathrm{kJ} / \mathrm{mol}^{[}$ & 13.7 & 16.8 & 20.7 & 24.6 \\
$\mathrm{wt} \mathrm{BsCspB}$ & $3200 \pm 200$ & $940 \pm 10$ & $330 \pm 20$ & $1.8 \pm 0.4$ \\
$\Delta G / \mathrm{kJ} / \mathrm{mol}^{\text {a] }}$ & 14.2 & 17.3 & 19.9 & 32.8 \\
\hline
\end{tabular}

[a] Data for wild type, wt, $B s C s p B$ were acquired at $T=288 \mathrm{~K}$ in $50 \mathrm{mM} \mathrm{Na}$ cacodylate, $\mathrm{pH} 7.0$ and $100 \mathrm{mM} \mathrm{KCl}$, and taken from reference [13a]. 
which have been probed in the present study. It has been quantitatively shown before that a variation of the position used for fluorine labeling of $B s C s p B$ goes e. g. with a variation of the overall thermodynamic stability of this protein $\left(\Delta G^{0}\right.$ wildtype $=$ $11.1 \pm 0.5 \mathrm{~kJ} \mathrm{~mol}^{-1} ; \quad \Delta G^{0}{ }_{5-19 F-\text { Trp-BsCspB }}=9.0 \pm 0.5 \mathrm{~kJ} \mathrm{~mol}^{-1}$; $\Delta G_{4-19 F-T r p-B S C \text { spB }}^{0}=12.7 \pm 1.1 \mathrm{~kJ} \mathrm{~mol}^{-1}$ ) while preserving overall structural characteristics. ${ }^{[17]}$ Note that an energetic difference of about $4 \mathrm{~kJ} \mathrm{~mol}^{-1}$ corresponds to a factor of about 5 comparing corresponding equilibrium constants at ambient conditions. Thus, we argue that site-specific fluorine labeling causes modest variations in inherent protein characteristics which may be responsible e.g. for modest differences in terms of ligand binding. This holds especially for high affinity binding events in the low nanomolar range. We additionally note that a change of buffer does not modify the binding affinity between single stranded DNA and fluorine labeled $5{ }^{-19} \mathrm{~F}-\operatorname{Trp}-B s \mathrm{CspB}$. Thus, applying sodium cacodylate or sodium phosphate buffer leads to a $K_{\mathrm{D}}$ value of comparable size (Figure S2E).

In a next step, we have analyzed the interaction of dT4 (Figure S3A-C), dT6 (Figure S4A-C), and dT7 (Figure S5A-C) with ${ }^{15} \mathrm{~N}$-labeled $5-{ }^{19} \mathrm{~F}$-Trp-BsCspB using two-dimensional heteronuclear ${ }^{1} \mathrm{H}^{-15} \mathrm{~N}$ HSQC NMR spectroscopy. The addition of equimolar amounts of an oligothymidine perturbs chemical shifts of cross-peaks illuminating the known binding site of $B s C s p B$ comprising predominantly residues $\mathrm{K} 13, \mathrm{~V} 28, \mathrm{~F} 30, \mathrm{~S} 31$, F38, K39, and T40 (Figures S3C, S4C, S5C). ${ }^{[14 a]}$ Note that the mean of changes of chemical shifts analyzed in $2 \mathrm{D}{ }^{1} \mathrm{H}-{ }^{15} \mathrm{~N}$ HSQC NMR spectra increases comparing the interaction of dT4 to $5-{ }^{19} \mathrm{~F}-\mathrm{Trp}-\mathrm{Bs} \mathrm{CspB}$ with experiments performed in presence of dT6 or dT7. Quantitatively, a twofold stoichiometric excess of dT6 or dT7 regarding $5-{ }^{19} \mathrm{~F}-T r p-B s C s p B$ leads to $\Delta \omega^{\text {mean }}=0.12 \pm$ $0.13 \mathrm{ppm}$ (Figures S4B, S5B) whereas $\Delta \omega^{\text {mean }}=0.07 \pm 0.09 \mathrm{ppm}$ is found for dT4 (Figure S3B) considering all backbone ${ }^{1} \mathrm{H}-{ }^{15} \mathrm{~N}$ correlations comprising $5-{ }^{19} \mathrm{~F}-\operatorname{Trp}-\mathrm{Bs} \mathrm{CspB}$. Thus, shortening the oligonucleotide results in an extenuated amplitude of changes of chemical shifts especially for G14, F38, and K39 exceeding the mean plus one standard deviation for adding dT6 or dT7 but not for the case of dT4. However, the overall pattern of changes of chemical shifts is qualitatively preserved (Figures S3C, S4C, and S5C). Note that the binding site determined here for the interaction of dT4, dT6, and dT7 with $5-{ }^{19} \mathrm{~F}$-Trp$B s C s p B$ (Figures S3C, 4C, and $5 C$ ) is fully comparable to the binding site found for wild type BsCspB (Figure 1). This can be further supported by an overlay of two-dimensional ${ }^{1} \mathrm{H}-{ }^{15} \mathrm{~N}$ HSQC NMR spectra comparing dT7-bound states acquired for wild type and $5-{ }^{19} \mathrm{~F}-$ Trp-BsCspB (Figure S5D). Both, signal heights and chemical shifts are almost identical for all ${ }^{1} \mathrm{H}-{ }^{15} \mathrm{~N}$ cross-peaks that are observed.

Thus, our data implies that the binding capacity of $B s C s p B$ to single stranded DNA molecules is conserved when wild type and fluorine labeled protein variants are compared. Quantitatively, deviations are of significance when the interaction between BsCspB and dT7 is followed even wild type and fluorine labeled protein variants possess highest affinity at this condition.

We have continued with the acquisition of ${ }^{19} \mathrm{~F}$ resonances of both $4-{ }^{19} \mathrm{~F}-\mathrm{Phe}-\mathrm{Bs} \mathrm{CspB}$ and $5{ }^{-19} \mathrm{~F}-\mathrm{Trp}-\mathrm{Bs} \mathrm{CspB}$, respectively, in free and oligonucleotide-bound states after proving the conservation of ligand binding characteristics comparing wild type and fluorine labeled $B s C s p B$ by fluorescence spectroscopy. First, the addition of dT4 or dT7 to $4-{ }^{19} \mathrm{~F}-\mathrm{Phe}-\mathrm{Bs} \mathrm{CspB}$ induces significant changes in the overall pattern of fluorine resonance signals (Figures $3 \mathrm{~A}$ and $\mathrm{S} 6 \mathrm{~A}$ ). Note that an 1.5 fold stoichiometric excess of an oligothymidine - that vary in length - regarding $4-{ }^{19} \mathrm{~F}-\mathrm{Phe}-\mathrm{Bs} \mathrm{CspB}$ induces a monotonic increase of the dispersion of chemical shifts, $\omega^{\text {dis }}$, comparing free state, $\omega^{\text {disfree }}=$ $3.55 \mathrm{ppm}$, with particular ligand-bound states: $\omega^{\mathrm{dis}, \mathrm{dT} 4}=$ $3.71 \mathrm{ppm}$ (Figure $3 \mathrm{~A}), \omega^{\mathrm{dis}, \mathrm{dT5}}=4.33 \mathrm{ppm}$ (Figure S6B), $\omega^{\mathrm{dis}, \mathrm{dT} 6}=$ $4.51 \mathrm{ppm}$ (Figure S6C), $\omega^{\mathrm{dis}, \mathrm{dT7}}=4.57 \mathrm{ppm}$ (Figure S6A). The generation of single point mutations enabled the partial assignment of fluorine resonances comprising $4-{ }^{19} \mathrm{~F}-\mathrm{Phe}-\mathrm{Bs} \mathrm{CspB}$ (Figures $3 \mathrm{~B}$ and $\mathrm{S} 7 \mathrm{~A}-\mathrm{G}$ ) allowing insights into ligand-to-protein interaction in a site-specific manner. Thus, solely the chemical shift of F49 does not change in presence of dT4, dT5, dT6 or dT7 (Figure S8). The change of the chemical shift of F38 depends on the length of oligonucleotide under study (Figure S8) whereas the resonance signal of F27 experiences the largest change in the chemical shift evaluating all phenylalanine residues (Figures $2 \mathrm{~B}$ and $\mathrm{S} 8$ ). All in all, chemical shifts of $\mathrm{F9}, \mathrm{F} 15$, $\mathrm{F} 17, \mathrm{~F} 27, \mathrm{~F} 30$ and $\mathrm{F} 38$ comprising $4-{ }^{19} \mathrm{~F}-\mathrm{Phe}-\mathrm{BsCspB}$ change by the addition of oligonucleotides that vary in length which is fully consistent with previous studies focusing on wild type $B s C s p B .{ }^{[13 a, d, 14 a, 15 a]}$ Note that differences in binding affinity observed for the interaction of dT4, dT5, dT6 and dT7 with $4-{ }^{19} \mathrm{~F}-\mathrm{Phe}-\mathrm{BsCspB}$ by fluorescence spectroscopy correlate with the overall change of chemical shifts as subsequently observed by fluorine NMR spectroscopy. An increase in binding affinity goes along with an increase in the dispersion of chemical shifts comparing dT4-, dT5-, dT6- and dT7-bound states.

In a next step, we took advantage of the simplicity of the fluorine NMR spectrum of $5-{ }^{19} \mathrm{~F}-\mathrm{Trp}-\mathrm{Bs} \mathrm{CspB}$ enabling a precise analysis of the chemical shift, signal height and line width of the single resonance signal upon addition of different oligonucleotides. Thus, the stepwise addition of dT4 induces a stepwise downfield shift of the chemical shift of W8 of about $\Delta \omega=$ $0.26 \mathrm{ppm}$ indicating the fast exchange regime (Figure $3 \mathrm{C}$ ). Analyzing the ratio of signal heights and line widths taking starting and end point of the titration experiment into account leads to 1.4 and 0.8 , respectively (Figure $4 \mathrm{~A}$ and Table S1). The presence of the fast exchange regime between dT4 and $5-{ }^{19} \mathrm{~F}$ $\operatorname{Trp}-B s \mathrm{CspB}$ enables to apply eq. (S1) to quantitatively determine the $K_{\mathrm{D}}$ value which leads to $K_{\mathrm{D}}=6.5 \pm 1.0 \mu \mathrm{M}$ (Figure 3D) mirroring the result independently obtained by fluorescence spectroscopy before (Table 1). Note that the NMR detected addition of $\mathrm{dT7}$ to $5-{ }^{19} \mathrm{~F}-\mathrm{Trp}-\mathrm{Bs} \mathrm{CspB}$ indicates the slow exchange regime (Figure S6D). The dT7-bound state of $5-{ }^{19} \mathrm{~F}-\operatorname{Trp}-\mathrm{Bs} C \mathrm{CspB}$ is upfield shifted by $\Delta \omega=0.19 \mathrm{ppm}$ regarding the free state indicating a structural difference to the dT4-bound state of $5-{ }^{19} \mathrm{~F}-\operatorname{Trp}-\mathrm{Bs} \mathrm{CspB}$ and hints, for this reason, to the difference in the strength of binding which has been experimentally observed (Table 1). Analyzing the ratio of signal heights and line widths taking starting and end point of this titration experiment into account leads to 0.3 and 3.1, respectively (Table S1). We have also performed a titration series using dT6 
A

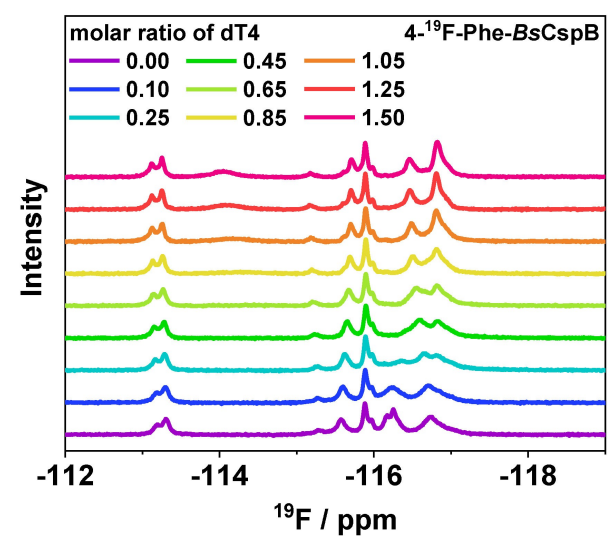

C

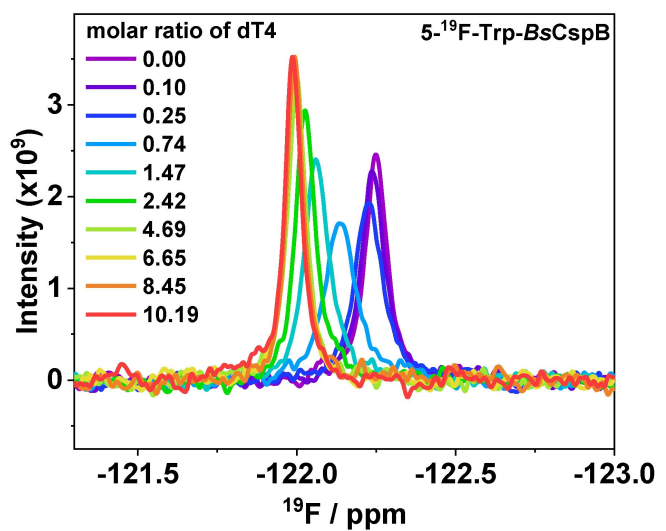

B

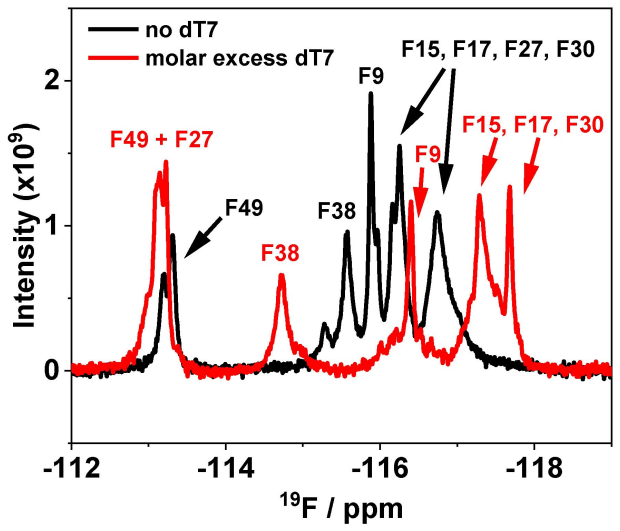

D

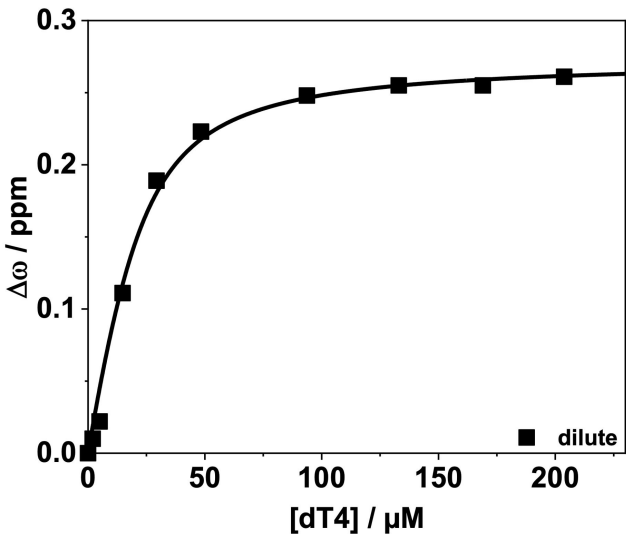

Figure 3. Probing the interaction between oligothymidines dT4 or dT7 and $4-{ }^{-19} \mathrm{~F}-\mathrm{Phe}-\mathrm{Bs} \mathrm{CspB}(\mathrm{A}, \mathrm{B})$ or $5-{ }^{19} \mathrm{~F}-\mathrm{Trp}-\mathrm{BsCspB}(\mathrm{C}, \mathrm{D})$ by following ${ }^{19} \mathrm{~F}$ NMR spectroscopic titration series under dilute conditions. The increasing molar ratio between oligothymidine and fluorine labeled $B s C s p B$ is shown by color coding as indicated. The concentration of $4-{ }^{19} \mathrm{~F}-\mathrm{Phe}-\mathrm{Bs} \mathrm{CspB}$ was set to $c=100 \mu \mathrm{M}$ as to $c=20 \mu \mathrm{M}$ for $5-{ }^{19} \mathrm{~F}-\operatorname{Trp}-\mathrm{Bs} \mathrm{CspB}$, respectively. (B) One-dimensional ${ }^{19} \mathrm{~F}$ NMR spectra of $4-{ }^{19} \mathrm{~F}$-Phe $B s C s p B$ (colored in black) and corresponding dT7-bound state (colored in red) are shown. The assignment of the resonance signals of phenylalanines is indicated by using $\mathrm{F}$ followed by the position in the primary sequence. Corresponding data are shown in Figure S6. (C) Probing the interaction between $\mathrm{dT} 4$ and $5{ }^{19}{ }^{19} \mathrm{~F}-\mathrm{Trp}-\mathrm{Bs} \mathrm{CspB}$ by high-resolution NMR spectroscopy. The change of the chemical shift of the fluorine resonance signal, $\Delta \omega$, has been determined for stepwise adding of dT4 under dilute condition. (D) Data fitting focusing on $\Delta \omega$ has been done according to eq. (S1) and the result is shown by using a continuous line. The binding affinity has been thus determined to $K_{\mathrm{D}}=6.5 \pm 1.0 \mu \mathrm{M}$.

and $5-{ }^{19} \mathrm{~F}-\mathrm{Trp}-\mathrm{Bs} \mathrm{CspB}$ leading to no difference in chemical shifts between free and dT6-bound states (Figure S6E) and completing the order in $\Delta \omega$ values (Table S1) which depicts the order found for the binding affinity of oligothymidines that vary in length by fluorescence spectroscopy before (Figure S1A, Table 1). Analyzing the ratio of signal heights and line widths taking starting and end point of adding dT6 to $5-{ }^{19} \mathrm{~F}-\operatorname{Trp}-\mathrm{Bs} \mathrm{CspB}$ into account leads to 0.3 and 2.8 , respectively, which are comparable to the values found for adding dT7 to $5-{ }^{19} \mathrm{~F}$-TrpBsCspB (Table S1).

To sum up, acquiring $1 \mathrm{D}{ }^{19} \mathrm{~F}$ NMR data monitoring the interaction between single stranded DNA varying in length and fluorine labeled $B s C s p B$ provides a reliable measure to precisely report on the binding process under dilute conditions. This is corroborated by the quantitative determination of the binding affinity between $\mathrm{dT} 4$ and $5-{ }^{19} \mathrm{~F}-\operatorname{Trp}-B s \mathrm{CspB}$ depicting $K_{\mathrm{D}}=6.5 \pm$
$1.0 \mu \mathrm{M}$ which mirrors the value found for binding of dT4 to wild type BsCspB.

Now we are in a position to reliably probe the interaction between oligothymidine and $B s C s p B$ in cell lysate as the full binding capacity of single stranded DNA to fluorine labeled $B s C s p B$ could be confirmed by applying fluorescence and multinuclear NMR spectroscopy before. Starting with $2 \mathrm{D}{ }^{1} \mathrm{H}-{ }^{15} \mathrm{~N}$ HSQC NMR experiments, ${ }^{1} \mathrm{H}$ and ${ }^{15} \mathrm{~N}$ chemical shifts obtained for ${ }^{15} \mathrm{~N}$ labeled $5-{ }^{19} \mathrm{~F}-$ Trp- $\mathrm{Bs} \mathrm{CspB}$ are not significantly modified when experimental conditions change from dilute to $c^{\text {cell lysate }}=130 \mathrm{~g} / \mathrm{L}$ indicating structural conservation. This holds for both, free $5-{ }^{19} \mathrm{~F}-\operatorname{Trp}-\mathrm{Bs} \mathrm{CspB}$ (Figure S9A) as well as its dT7-bound states (Figure S9B). Quantitatively, the mean of the change of chemical shifts comparing dilute with cell lysate conditions is determined to $\Delta \omega=0.024 \pm 0.020 \mathrm{ppm}$ (free states) as well as to $\Delta \omega=0.015 \pm 0.025 \mathrm{ppm}$ (dT7-bound states) reporting on backbone resonances comprising $5-{ }^{19} \mathrm{~F}-\mathrm{Trp}-\mathrm{BsCspB}$. Thus, chang- 
A

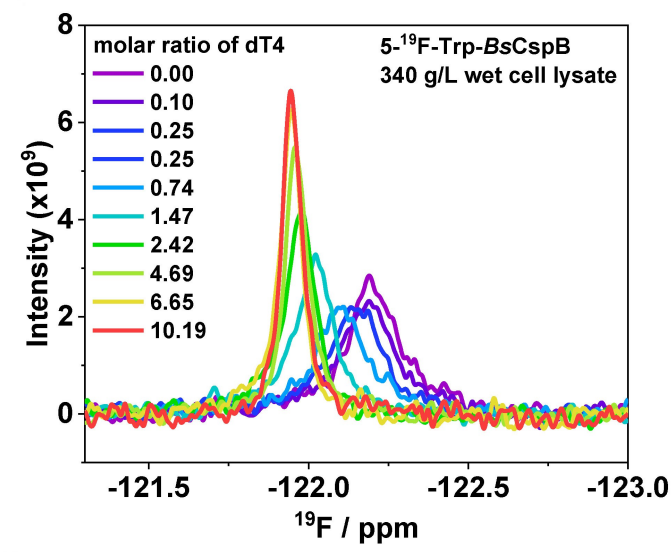

C

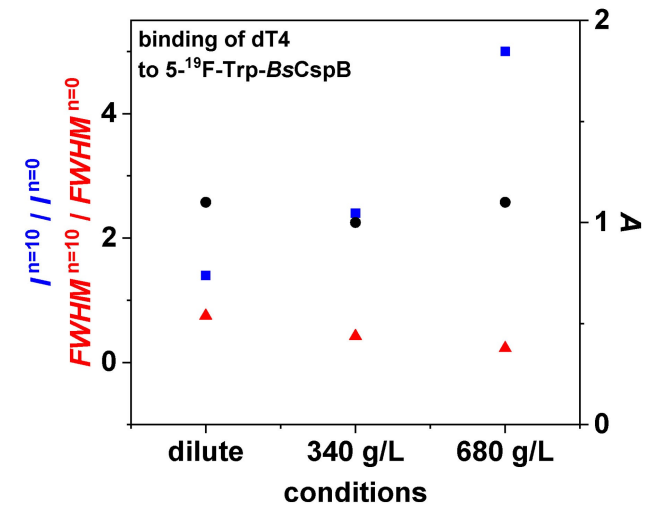

B

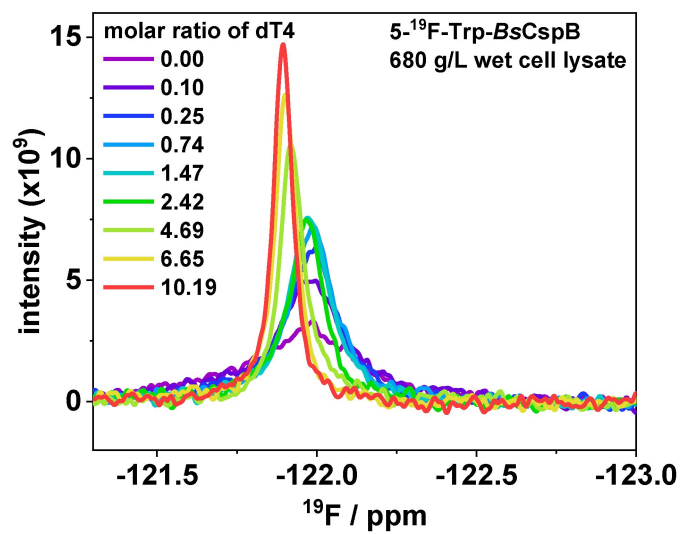

Figure 4. Probing and quantification of the interaction between $\mathrm{dT} 4$ and $5-{ }^{19} \mathrm{~F}-\mathrm{Trp}-\mathrm{Bs} \mathrm{CspB}$ at varying conditions by following ${ }^{19} \mathrm{~F}$ NMR spectroscopic titration series. Cell lysate concentration of $340 \mathrm{~g} / \mathrm{L}(\mathrm{A})$ as well as $680 \mathrm{~g} / \mathrm{L}(\mathrm{B})$ of wet cell lysate have been particularly applied. The increasing molar ratio between oligothymidine and fluorine labeled $B s \mathrm{CspB}$ is shown by color coding as indicated. The protein concentration was set to $c=20 \mu \mathrm{M}$. (C) Progression of ratio of signal heights I (rectangles, colored in blue, left $y$-axis), ratio of line widths FWHM (triangles, colored in red, left $y$-axis) and the product $A$ of both (circles, colored in black, right $y$-axis) focusing on starting $(n=0)$ and end point $(n=10)$ of the titration series evaluated at dilute and cell lysate conditions differing in concentration. Accompanying data are presented in Table S1.

ing from dilute to cell-like conditions results in - if at all - little structural alterations monitoring free as well as dT7-bound state of $5-{ }^{19} \mathrm{~F}-$ Trp-BsCspB. Consequently, turning to ${ }^{19} \mathrm{~F}$ NMR spectroscopy enables to precisely follow the interaction between oligothymidines and $5-{ }^{19} \mathrm{~F}-\operatorname{Trp}-\mathrm{Bs} \mathrm{CspB}$ in cell lysate in great spectroscopic detail by analyzing signal height, line width and the chemical shift focusing on a single fluorine resonance signal. Note that we have already made use of the spectral simplicity of fluorine detected NMR data for $5-{ }^{19} \mathrm{~F}-\operatorname{Trp}-B s \mathrm{CspB}$ under dilute conditions even enabling to determine the binding affinity quantitatively for the interaction with dT4 (Figure 3C, D).

Thus, we have followed the single fluorine resonance of $5-{ }^{19} \mathrm{~F}-\mathrm{Trp}-\mathrm{Bs} \mathrm{CspB}$ by the stepwise addition of dT4 (Figure 4A, B), dT6 (Figure S10A, B), and dT7 (Figure S10C, D) using different concentrations of cell lysate. Focusing on the interaction with dT4, increasing cell lysate concentration to $c=340 \mathrm{~g} / \mathrm{L}$ (Figure $4 \mathrm{~A}$ ) and even further to $c=680 \mathrm{~g} / \mathrm{L}$ (Figure $4 \mathrm{~B}$ ) changes the overall pattern observed for the single fluorine resonance signal of $5-{ }^{19} \mathrm{~F}-\operatorname{Trp}-\mathrm{Bs} \mathrm{CspB}$ compared to the titration experiment performed under dilute conditions (Figure $3 \mathrm{~A}$ ). Consequently, we have expanded the analysis of one-dimensional fluorine NMR data to signal heights and line widths to enable further quantitative insights of the interaction between oligothymidines and fluorine labeled $B s C s p B$ as followed in complex environments. The product of the ratio of signal heights, $l^{\text {end }} /$ $1^{\text {start }}$, and the ratio of line widths, $F W H M^{\text {end }} / F W H M^{\text {start }}$, calculated for starting and end points of binding experiments performed for dT4 under dilute, $c^{\text {cellysate }}=340 \mathrm{~g} / \mathrm{L}$ and $c^{\text {cell lysate }}=680 \mathrm{~g} / \mathrm{L}$ conditions (Figure $4 \mathrm{C}$ ) and for all experiments undertaken for adding dT6 and dT7 remains constant with $I^{\text {end }} / I^{\text {start }} * F_{W H M^{\text {end }} /}$ $F W H M^{\text {start }} \cong 1$ (Table S1). This strongly confirms the stability and reliability of fluorine labeled $B s C s p B$ during the time course of the experiments undertaken here.

Contrary, individual values obtained for $/^{\text {end }} / \rho^{\text {start }}$ and $F W H M^{\text {end }} / F W H M^{\text {start }}$ differ systematically comparing the three conditions (Table S1). The ratio of line widths decreases whereas the ratio of signal heights increases monotonically with increasing concentration of cell lysate (Table S1). Line width of the single fluorine resonance signal reporting on free $5-{ }^{19} \mathrm{~F}$-Trp$B s C s p B$ increases significantly with increasing concentration of 
cell lysate $\left(F W H M^{\text {dilute }}=59 \mathrm{~Hz}, F W H M^{340 \mathrm{~g} / \mathrm{L}}=128 \mathrm{~Hz}, F W H M^{680 \mathrm{~g} /}\right.$ $\mathrm{L}=242 \mathrm{~Hz}$ ) considering the significant increase in solvent viscosity. In contrast, line width of the resonance signal representing dT4-bound $5-{ }^{19} \mathrm{~F}-\mathrm{Trp}-\mathrm{Bs} \mathrm{CspB}$ remains almost constant $\quad\left(F W H M^{\text {dilute }}=45 \mathrm{~Hz}, \quad F W H M^{340} \mathrm{~g} / \mathrm{L}=54 \mathrm{~Hz}, \quad F W H M^{680 \mathrm{~g} / \mathrm{L}}=\right.$ $53 \mathrm{~Hz}$ ) suggesting a highly dynamic ligand-to-protein interaction even in highly concentrated cell lysate. Note that the difference in chemical shift between free and dT4-bound $5-{ }^{19} \mathrm{~F}$ $\operatorname{Trp}-B s C s p B$ significantly decreases comparing dilute conditions possessing $\Delta \omega=0.26 \mathrm{ppm}$ (Figure $3 \mathrm{C}$ ) with $c^{\text {cell lysate }}=680 \mathrm{~g} / \mathrm{L}$ possessing $\Delta \omega=0.1 \mathrm{ppm}$ (Figure $4 \mathrm{~B}$ ). This significant decrease of $\Delta \omega$ value and the drastic change in line width upon addition of dT4 to $5^{-19} \mathrm{~F}-\mathrm{Trp}-\mathrm{Bs} \mathrm{CspB}$ in $c^{\text {cell lysate }}=680 \mathrm{~g} / \mathrm{L}$ shifts the binding process from fast to the slow-to-intermediate exchange regime preventing a reliable quantitative determination of the binding affinity at this condition. Potentially, high cell lysate concentration of $680 \mathrm{~g} / \mathrm{L}$ comprises target molecules which may already interact with $5-{ }^{19} \mathrm{~F}-\operatorname{Trp}-B s \mathrm{CspB}$ in the absence of oligothymidines (Figure S11A) while moving the chemical shift already in the direction of bound state. But adding stoichiometric excess of dT4 to $5-{ }^{19} \mathrm{~F}-\operatorname{Trp}-\mathrm{Bs} \mathrm{CspB}$ at this high concentration of cell lysate leads to a fluorine resonance signal possessing line width which has been observed before under both dilute and $c^{\text {celllysate }}=340 \mathrm{~g} / \mathrm{L}$ conditions (Figure S11B). This suggests that dT4 is still fully capable to occupy the binding site offered by $5{ }^{19} \mathrm{~F}$-Trp-BsCspB in a highly complex environment even the ligand affinity is in the micromolar range. The same observation is made for dT6- and dT7-bound states both possessing a ligand affinity in the nanomolar range (Figure $\mathrm{S} 11 \mathrm{C}, \mathrm{D})$. In other words, BsCspB is capable to specifically interact with dT4, dT6, and dT7 even in presence of a high concentration of cell lysate.

Following the fluorine chemical shift of $5-{ }^{19} \mathrm{~F}-\operatorname{Trp}-B s \mathrm{CspB}$ while adding dT4 in $c^{\text {celllysate }}=340 \mathrm{~g} / \mathrm{L}$ enables the quantitative determination of the binding affinity which results in $K_{\mathrm{D}}=6.8 \pm$ $1.1 \mu \mathrm{M}$ (Figure S12). Note that this $K_{\mathrm{D}}$ value precisely mirrors the result found under dilute conditions (Figure S3D). Moving on, probing the interaction of $\mathrm{dT7}$ to $5-{ }^{19} \mathrm{~F}-\mathrm{Trp}-\mathrm{Bs} \mathrm{CspB}$ leads to an increase in signal height as well as a monotonic decrease in line width with increasing cell lysate concentration (Table S1) when free and dT7-bound states are compared (Figure S11C). Line width of the resonance signal representing dT7-bound $5-{ }^{19} \mathrm{~F}$ Trp-BsCspB remains almost constant applying different conditions $\left(F W H M^{\text {dilute }}=152 \mathrm{~Hz}, F W H M^{130 \mathrm{~g} / \mathrm{L}}=160 \mathrm{~Hz}, F W H M^{300 \mathrm{~g} / \mathrm{L}}=\right.$ $140 \mathrm{~Hz}$ ) confirming the observation made for the addition of dT4 before. Note that a reliable quantitative determination of the binding affinity between $\mathrm{dT} 7$ and $5-{ }^{19} \mathrm{~F}-\operatorname{Trp}-B s \mathrm{CspB}$ is prohibited as this interaction takes place on the slow-tointermediate exchange regime.

Finally, we have probed the interaction between dT6 and $5-{ }^{19} \mathrm{~F}-\mathrm{Trp}-\mathrm{BsCspB}$ applying $c^{\text {celllysate }}=135 \mathrm{~g} / \mathrm{L}$ and $c^{\text {celllysate }}=210 \mathrm{~g} /$ $L$ (Figure S11D) and made a comparison to dilute conditions (Figure S6E). The unaltered chemical shift observed under dilute conditions when free and dT6-bound states of $5-{ }^{19} \mathrm{~F}-\mathrm{Trp}-\mathrm{Bs} \mathrm{CspB}$ are compared (Figure S6E) is also seen in presence of $c^{\text {cell lysate }}=$ $135 \mathrm{~g} / \mathrm{L}$ (Figure S11D) and $c^{\text {celllysate }}=210 \mathrm{~g} / \mathrm{L}$ (Figure S11D). Additionally, the similarity found for the ratio of signal heights and line widths taking starting and end point of adding dT6 or dT7 to $5{ }^{19} \mathrm{~F}$-Trp-BsCspB under dilute conditions is also seen when the respective values are compared in cell lysate (Table S1). Note that a quantitative determination of the binding affinity of dT6 regarding $5-{ }^{19} \mathrm{~F}-\operatorname{Trp}-\mathrm{Bs} \mathrm{CspB}$ is not feasible due to the spectral overlay between free and dT6-bound states of $5-{ }^{19} \mathrm{~F}-$ Trp-BsCspB (Figures S6E and S11D). And, again, line width of the resonance signal representing $d \mathrm{~d} 6$-bound $5-{ }^{19} \mathrm{~F}-\operatorname{Trp}-\mathrm{Bs} \mathrm{CspB}$ remains almost constant applying different conditions $\left(F W H M^{\text {dilute }}=160 \mathrm{~Hz}, F W H M^{135 \mathrm{~g} / \mathrm{L}}=180 \mathrm{~Hz}, F W H M^{210 \mathrm{~g} / \mathrm{L}}=160 \mathrm{~Hz}\right)$ confirming the observations made before for dT4- and dT7bound $5-{ }^{19} \mathrm{~F}-$ Trp-BsCspB (Figures S11B, C).

Finally, we have applied line shape analysis using a third independent method to quantitatively determine binding affinity between single stranded DNA and fluorine labeled $B s C s p B$ under different conditions. ${ }^{[20]}$ Recently, line shape analysis was successfully applied to quantify the binding of proline-rich peptides differing in primary sequence to a $\mathrm{SH} 3$ domain while analyzing fluorine NMR resonances. ${ }^{[21]}$ Also, crowded environments comprising sugar, urea, and protein molecules have been applied to evaluate the energetics of this protein-to-peptide interaction applying line shape analysis of fluorine NMR resonances. ${ }^{[2]}$ Note that line shape analysis enables to determine kinetic parameters quantifying a dynamic process in terms of association, $k_{\mathrm{on}}$, and dissociation rate constants, $k_{\text {off }}$ focusing on the progression of chemical shifts, signal heights and line shapes of an NMR resonance signal in an NMR titration experiment. Consequently, the ratio between $k_{\text {off }}$ and $k_{\text {on }}$ values gives direct access to the dissociation constant, $K_{\mathrm{D}}=k_{\text {off }} / k_{\mathrm{on}}$, reporting on e.g. ligand-to-protein binding and which can then be used for a comparison with the $K_{\mathrm{D}}$ value that has been determined by another experimental method.

The NMR titration series performed here between $\mathrm{dT} 4$ and $5-{ }^{19} \mathrm{~F}-$ Trp-BsCspB under dilute (Figure $3 \mathrm{~A}$ ) and $c^{\text {cell lysate }}=340 \mathrm{~g} / \mathrm{L}$ conditions (Figure 4A) have thus been evaluated using NMRLineGuru ${ }^{[19]}$ enabling to quantify the binding event. As a result, the ligand binding affinity is determined to $K_{\mathrm{D}}^{\text {dilute }}=$ $5.7 \mu \mathrm{M}$ and $K_{\mathrm{D}}{ }^{340 \mathrm{~g} / \mathrm{L}}=5.6 \mu \mathrm{M}$, respectively, assuming a two-state binding process (Figure $5 \mathrm{~A}, \mathrm{~B}$ ). Note that these $K_{\mathrm{D}}$ values agree very well with affinities independently determined by both fluorescence (Table 1) and NMR chemical shifts (Figures 3D and S12) before. Additionally, the analysis of NMR line shapes also reports on the kinetics of the binding process which leads to a rate constant of dissociation of $k_{\text {off }}=1170 \mathrm{~s}^{-1}$ (dilute conditions) as well as $k_{\text {off }}=1270 \mathrm{~s}^{-1}$ (cellysate $=340 \mathrm{~g} / \mathrm{L}$ ) in our study. Thus, the kinetics of the binding process between dT4 and BsCspB does not quantitatively change when dilute and $c^{\text {celllysate }}=$ $340 \mathrm{~g} / \mathrm{L}$ are compared. Thereby it can be concluded that the identity of both $K_{\mathrm{D}}$ and $k_{\text {off }}$ values determines also an invariance of the rate constant of association, $k_{\text {on }}$, when the two experimental conditions are compared. We note that a reliable quantitative line shape analysis for the interaction of dT4 to $5-{ }^{19} \mathrm{~F}-\operatorname{Trp}-B s \mathrm{CspB}$ at $c^{\text {cell lysate }}=680 \mathrm{~g} / \mathrm{L}$ cannot be performed. This is based on the fact that the fluorine resonance signal reporting on $5-{ }^{19} \mathrm{~F}-\mathrm{Trp}-\mathrm{Bs} \mathrm{CspB}$ is already shifted in the direction of the bound state at this condition. 
A

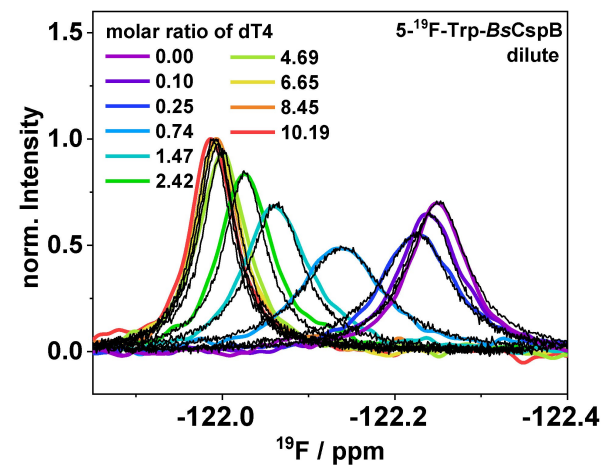

B

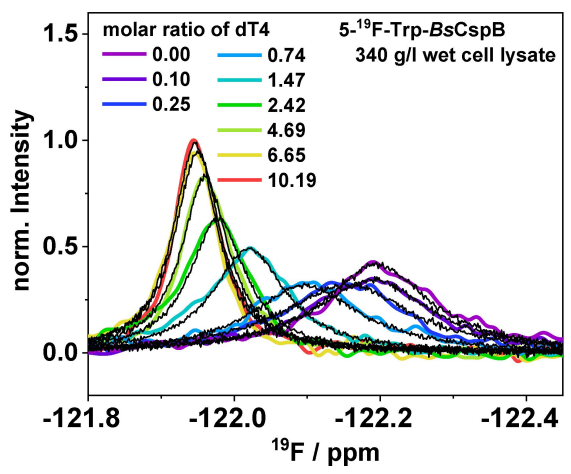

Figure 5. Comparing simulated and experimentally acquired fluorine NMR data following the interaction between $\mathrm{dT} 4$ and $5-{ }^{19} \mathrm{~F}-\mathrm{Trp}-\mathrm{Bs} \mathrm{CspB}(\mathrm{c}=20 \mathrm{MM})$. Application of NMRLineGuru ${ }^{[19]}$ leads to $K_{\mathrm{D}}=5.7 \mu \mathrm{M}$ and $k_{\text {off }}=1170 \mathrm{~s}^{-1}$ for dilute conditions (A) as to $K_{\mathrm{D}}=5.6 \mu \mathrm{M}$ and $k_{\text {off }}=1270 \mathrm{~s}^{-1}$ applying $c=340 \mathrm{~g} / \mathrm{L}$ cell lysate (B). NMR data are shown in color whereas simulations are colored in black.

\section{Conclusion}

All in all, we have shown that fluorine NMR spectroscopy allows to precisely follow binding of single stranded DNA molecules to its target protein in cell lysate. A quantitative analysis of the binding event shows a conservation of ligand binding affinity and kinetics when dilute and cell lysate conditions are compared. Our data imply that the presence of cell lysate does not significantly modify the interaction between a ligand and its target protein - holding at least for the case of BsCspB as presented here. This observation has been made in particular for binding affinities ranging between $50 \mathrm{nM}$ and $10 \mu \mathrm{M}$ and increasing cell lysate concentrations in the hundreds of $\mathrm{g} / \mathrm{L}$. We are convinced that the methodology outlined in our manuscript provides a promising approach for the quantitative determination of the binding affinity which characterizes nucleic acidto-protein interaction directly in the cell.

\section{Acknowledgements}

We thank the members of our group for discussion and the Deutsche Forschungsgemeinschaft for financial support (KO4687) 4-1). Open Access funding enabled and organized by Projekt DEAL.

\section{Conflict of Interest}

The authors declare no conflict of interest.

Keywords: cell lysate $\cdot$ NMR spectroscopy $\cdot$ protein folding

[1] P. H. von Hippel, J. D. McGhee, Annu. Rev. Biochem. 1972, 41, 231-300.

[2] a) P. H. Von Hippel, O. G. Berg, Proc. Natl. Acad. Sci. USA 1986, 83, 1608 1612; b) F. He, W. Borcherds, T. Song, X. Wei, M. Das, L. Chen, G. W. Daughdrill, J. Chen, Proc. Natl. Acad. Sci. USA 2019, 116, 8859-8868.
[3] S. B. Zimmerman, S. O. Trach, J. Mol. Biol. 1991, 222, 599-620.

[4] M. C. Cheung, R. LaCroix, B. K. McKenna, L. Liu, J. Winkelman, D. J. Ehrlich, Cytometry Part A 2013, 83, 540-551.

[5] a) S. Cayley, B. A. Lewis, H. J. Guttman, M. T. Record, J. Mol. Biol. 1991 , 222, 281-300; b) E. Puchkov, Biochem. Moscow Suppl. Ser. A 2013, 7, 270-279.

[6] a) E. C. Tse, T. J. Zwang, J. K. Barton, J. Am. Chem. Soc. 2017, 139, 12784 12792; b) A. I Lacroix, T. G. Edwardson, M. A. Hancock, M. D. Dore, H. F. Sleiman, J. Am. Chem. Soc. 2017, 139, 7355-7362; c) M. HyjekSkładanowska, T. A. Vickers, A. Napiórkowska, B. A. Anderson, M. Tanowitz, S. T. Crooke, X.-h. Liang, P. P. Seth, M. Nowotny, J. Am. Chem. Soc. 2020, 142, 7456-7468; d) P. R. Blier, A. J. Griffith, J. Craft, J. A. Hardin, J. Biol. Chem. 1993, 268, 7594-7601.

[7] a) M. M. Dedmon, C. N. Patel, G. B. Young, G. J. Pielak, Proc. Natl. Acad. Sci. USA 2002, 99, 12681-12684; b) L. M. Luh, R. Hänsel, F. Löhr, D. K. Kirchner, K. Krauskopf, S. Pitzius, B. Schäfer, P. Tufar, I. Corbeski, P. Güntert, J. Am. Chem. Soc. 2013, 135, 13796-13803; c) A. Christiansen, P. Wittung-Stafshede, Biophys. J. 2013, 105, 1689-1699; d) C. Echeverria, R. Kapral, Phys. Chem. Chem. Phys. 2012, 14, 6755-6763; e) B. Akabayov, S. R. Akabayov, S.-J. Lee, G. Wagner, C. C. Richardson, Nat. Commun. 2013, 4, 1-10; f) N. F. Dupuis, E. D. Holmstrom, D. J. Nesbitt, Proc. Natl. Acad. Sci. USA 2014, 111, 8464-8469; g) S. Sukenik, M. Salam, Y. Wang, M. Gruebele, J. Am. Chem. Soc. 2018, 140, 10497-10503; h) B. Köhn, M. Kovermann, ChemBioChem 2019, 20, 759-763; i) J. Danielsson, X. Mu, L. Lang, H. Wang, A. Binolfi, F.-X. Theillet, B. Bekei, D. T. Logan, P. Selenko, H. Wennerström, Proc. Natl. Acad. Sci. USA 2015, 112, 12402-12407; j) A. E. Smith, L. Z. Zhou, A. H. Gorensek, M. Senske, G. J. Pielak, Proc. Natl. Acad. Sci. USA 2016, 113, 1725-1730; k) I. König, A. Soranno, D. Nettels, B. Schuler, Angew. Chem. Int. Ed. 2021, 60, 10724-10729; I) F. Zosel, A. Soranno, K. J. Buholzer, D. Nettels, B. Schuler, Proc. Natl. Acad. Sci. USA 2020, 117, 13480-13489; m) A. P. Minton, Biophys. J. 2000, 78, 101-109; n) J. Hong, L. M. Gierasch, J. Am. Chem. Soc. 2010, 132, 1044510452; o) A. J. Guseman, S. L. Speer, G. M. Perez Goncalves, G. J. Pielak, Biochemistry 2018, 57, 1681-1684; p) A. C. Miklos, M. Sarkar, Y. Q. Wang, G. J. Pieak, J. Am. Chem. Soc. 2011, 133, 7116-7120; q) M. Sarkar, A. E. Smith, G. J. Pielak, Proc. Natl. Acad. Sci. USA 2013, 110, 19342-19347; r) B. Köhn, M. Kovermann, Nat. Commun. 2020, 11, 1-10.

[8] a) B. Mateos, M. Sealey-Cardona, K. Balazs, J. Konrat, G. Staffler, R. Konrat, Angew. Chem. Int. Ed. 2020, 132, 3914-3918; b) I. Alshamleh, N. Krause, C. Richter, N. Kurrle, H. Serve, U. L. Günther, H. Schwalbe, Angew. Chem. Int. Ed. 2020, 132, 2324-2328; c) T. Tanaka, T. Ikeya, H. Kamoshida, Y. Suemoto, M. Mishima, M. Shirakawa, P. Güntert, Y. Ito, Angew. Chem. Int. Ed. 2019, 58, 7284-7288; Angew. Chem. 2019, 131, 7362-7366.

[9] Y. Ito, V. Dötsch, M. Shirakawa, In-cell NMR spectroscopy: from molecular sciences to cell biology, Royal Society of Chemistry, 2019.

[10] a) M. A. Danielson, J. J. Falke, Annu. Rev. Biophys. Biomol. Struct. 1996, 25, 163; b) J. Gerig, Prog. Nucl. Magn. Reson. Spectrosc. 1994, 26, 293370; c) S. L. Cobb, C. D. Murphy, J. Fluorine Chem. 2009, 130, 132-143.

[11] a) H. Schindelin, M. A. Marahiel, U. Heinemann, Nature 1993, 364, 164168; b) A. Schnuchel, R. Wiltscheck, M. Czisch, M. Herrler, G. Willimsky, P. Graumann, M. A. Marahiel, T. A. Holak, Nature 1993, 364, 169-171. 
[12] a) J. Sommerville, M. Ladomery, FASEB J. 1996, 10, 435-443; b) W. N. Jiang, Y. Hou, M. Inouye, J. Biol. Chem. 1997, 272, 196-202; c) W. H. Bae, B. Xia, M. Inouye, K. Severinov, Proc. Natl. Acad. Sci. USA 2000, 97, 77847789.

[13] a) M. Zeeb, K. E. Max, U. Weininger, C. Löw, H. Sticht, J. Balbach, Nucleic Acids Res. 2006, 34, 4561-4571; b) H. P. Morgan, P. Estibeiro, M. A. Wear,

K. E. Max, U. Heinemann, L. Cubeddu, M. P. Gallagher, P. J. Sadler, M. D. Walkinshaw, Nucleic Acids Res. 2007, 35, e75; c) M. M. Lopez, K. Yutani, G. I. Makhatadze, J. Biol. Chem. 1999, 274, 33601-33608; d) K. Schröder, P. Graumann, A. Schnuchel, T. A. Holak, M. A. Marahiel, Mol. Microbiol. $1995,16,699-708$.

[14] a) K. E. Max, M. Zeeb, R. Bienert, J. Balbach, U. Heinemann, J. Mol. Biol. 2006, 360, 702-714; b) R. Sachs, K. E. Max, U. Heinemann, J. Balbach, RNA 2012, 18, 65-76.

[15] a) M. Zeeb, J. Balbach, Protein Sci. 2003, 12, 112-123; b) R. Bandziulis, M. Swanson, G. Dreyfuss, Genes Dev. 1989, 3, 431-437; c) C. G. Burd, G. Dreyfuss, Science 1994, 265, 615-621.

[16] H. Welte, M. Kovermann, Protein Expression Purif. 2019, 157, 86-91.
[17] H. Welte, T. Zhou, X. Mihajlenko, O. Mayans, M. Kovermann, Sci. Rep. 2020, 10, 1-12.

[18] H. Welte, M. Kovermann, ChemBioChem 2020, 21, 3575.

[19] C. Feng, E. L. Kovrigin, C. B. Post, Sci. Rep. 2019, 9, 1-14.

[20] A. Furukawa, T. Konuma, S. Yanaka, K. Sugase, Prog. Nucl. Magn. Reson. Spectrosc. 2016, 96, 47-57.

[21] S. S. Stadmiller, J. S. Aguilar, C. A. Waudby, G. J. Pielak, Biophys. J. 2020 $118,2537-2548$.

[22] S. S. Stadmiller, J. S. Aguilar, S. Parnham, G. J. Pielak, J. Phys. Chem. B 2020, 124, 9297-9309.

Manuscript received: June 19, 2021

Revised manuscript received: July 30, 2021

Accepted manuscript online: August 13, 2021

Version of record online: September 3, 2021 